\title{
HLA-A1 Positive Cells Present
}

National Cancer Institute

\section{Source}

National Cancer Institute. HLA-A1 Positive Cells Present. NCI Thesaurus. Code C69407.

A laboratory test result indicating the presence of HLA-A*01 positive cells in a tissue sample. 